\title{
Mobility and Elite Cues: Partisan Responses to Covid-19
}

\author{
James Bisbee \\ NeW YORK UNIVERSITY
}

\author{
Da In Lee \\ Columbia University
}

This version: July 30, 2020

\begin{abstract}
Scholars have long demonstrated the power of partisan cues on the public's political views, but it is unclear to what extent this power spills over to non-political spheres. We test whether elite cues on Covid-19 influence social distancing behavior amid overwhelming information about the health risks. We start by confirming that counties which voted for Trump in 2016 were less likely to shelter in place than counties which supported Clinton. Using Trump's skepticism about the severity of the pandemic, we show that Republican-leaning counties were more likely to shelter in place when Trump took the virus seriously. We evaluate the relative importance of elite cues and objective facts on shelter-in-place behaviors via variable importance tests, confirming that Trump's pronouncements play a significant role, particularly in Republican counties. These patterns reflect a story in which elite cues influence not just costless political attitudes, but real-world behaviors with life and death consequences.
\end{abstract}

\section{8,046 Words}

Elite cues | Motivated reasoning | Theory testing | Covid-19 
Scholars have long noted the strong connection between politicians' position-taking and public opinion. A rich body of research provides evidence of citizens adopting politicians' positions as their own (Abramowitz, 1978; Achen and Bartels, 2016; Berelson, Lazarsfeld and McPhee, 1954; Berelson, Gaudet and Lazarsfeld, 1968; Campbell et al., 1960; Carsey and Layman, 2006; Lenz, 2012; Minozzi et al., 2015).

Representing this work, (Rahn, 1993, 492) writes that citizens "neglect policy information in reaching evaluations" even when they are exposed to such information. Instead, they "use the [party] label rather than policy attributes in drawing inferences." Even when "citizens are well informed, they react mechanically to political ideas on the basis of external cues about their partisan implications" and "fail to reason for themselves about the persuasive communications they encounter" unless those communications are extremely clear (Zaller, 1992, 45). In this view, individuals blindly adjust their policy views to align with their partisan leaders, rather than choosing politicians and parties based on innate policy preferences (Lenz, 2012).

Despite mounting evidence of the primacy of elite cues, much of the existing research focuses on outcomes that are relatively costless, such as survey responses or evaluations of a party or a co-partisan politician (Broockman and Butler, 2017; Lenz, 2012; Zaller, 1992). For example, Lenz (2012) uses panel survey data to show that voters change their positions across a variety of policy positions to align with their preferred candidates or party. Similarly, Broockman and Butler (2017) uses a survey experiment to identify the relationship between legislators' issue position and constituents' views across policy issues. These statements of preference, especially those revealed through surveys, are arguably cheap talk proxies for true political beliefs, allowing individuals to reap the cognitive benefits of cheer-leading copartisans at minimal cost to sincerity (Cavaillé, Chen and Van der Straeten, 2020). Holding a belief about the economy or a preference over the optimal policy are often not stances that will immediately, or directly, affect an individual's welfare. It is an open question whether 
partisan affiliation influences non-political behaviors that carry real welfare costs, although existing research suggests that objective welfare attenuates partisan motivated reasoning (Bullock et al., 2013; Chen, 2013; Prior et al., 2015).

In this paper, we examine the effect of partisan elite cues on a more costly real-world behavior - how individuals respond to a life-threatening pandemic upon receiving different signals from their political leaders. Using GPS data to measure individuals' level of mobility over the onset of Covid-19, we show that counties which supported Trump in the 2016 presidential election are less likely to adopt risk-minimizing behaviors. More importantly, we explore the variation in counties' social distancing behavior as a function of President Trump's elite cues regarding Covid-19, issued via Twitter. We show that the partisan differences across counties are sensitive to Trump's pronouncements regarding the severity of the pandemic, and that this sensitivity is stronger among Republican-leaning than Democratleaning counties. We argue that these empirical patterns are consistent with a story in which elite cues influence not just costless responses to a survey, but real-world behaviors with life and death consequences.

\section{Theory and Empirical Context}

Many studies have considered the effects of partisan cues on voters' political views. A prominent generalization from this line of research is that voters are far more affected by partisan cues than policy information when they are exposed to both. Most citizens do not know what they want government to do, and they do not keep themselves informed about most of the problems government faces (Downs, 1957). Even when one is informed on important attributes of a policy, their attitude toward the policy depends "almost exclusively upon the stated position of one's own political party" (Cohen, 2003, 808). McGuire (1969, 198) writes that a citizen relies heavily on source cues and tries to master the message contents only 
when it is absolutely necessary." These claims have also been tested in an experimental setting by Broockman and Butler (2017) who find that voters do not evaluate their legislators more negatively when representatives take positions these voters had previously opposed, regardless of whether the representatives justified their stance.

In one of the most influential pieces on the dynamics of public opinion, Zaller (1992) draws on theoretical models from cognitive psychology and argues that the combination of political awareness, political orientation, and elite communication determine individuals' opinions. When elites present a clear picture of what should be done, people see events from that point of view, with the most attentive people being those most likely to adopt the elite position. When elites are divided, people adopt the position held by their co-partisan elite, again with the most attentive people cleaving most sharply along the ideological divisions. Therefore, opinion leadership by elites engenders stereotypes, frames of reference, and cues that enable people to form conceptions and opinions about events that are beyond their full personal understanding (Zaller, 1992, chap. 6).

Under the broad umbrella of elite cues resides a variety of competing theoretical explanations for their importance. On the one hand, scholars argue that elite cues act as "information heuristics," allowing voters to save themselves the cost of being informed on a wide range of policy issues (Downs, 1957; Popkin, 1994; Cacioppo and Petty, 1984; Kruglanski and Webster, 1996; Mackie and Cooper, 1984). ${ }^{1}$ On the other hand, elite cues contribute to a process of partisan motivated reasoning in which individuals attempt to maintain their beliefs in the face of attitude-challenging information (Kunda, 1990; Lodge and Taber, 2006, 2013). Citizens' identification with a political party colors how they perceive reality, and they can obtain psychic benefits from selectively attributing credit to their party for fa-

\footnotetext{
${ }^{1}$ Relevant for our contemporary focus, Hetherington (2001) extends the implication of this argument to mass polarization in the context of the United States, arguing that growing partisan polarization produces more clearly differentiated elite cues, making it even easier for co-partisans to make distinctions and adopt policy issues along party lines.
} 
vorable policy outcomes, while blaming the opposing party for unfavorable policy outcomes. Even when partisans may acknowledge the same reality, they may find other ways of aligning undeniable realities with their party loyalties (Bisgaard, 2015; Cavaillé, Chen and Van der Straeten, 2020; Miller, Saunders and Farhart, 2016).

These perspectives differ in the mechanisms by which beliefs are formed, but agree in their skepticism over an individual's ability to update her political views based on objective facts. Insofar as the normative appeal of democracy hinges on this updating process, these perspectives question the very value of democratic institutions. Unsurprisingly, these views have not gone unchallenged.

Notably, Bullock (2011) argues that previous studies are unable to compare the effects of policy attributes and position-taking by party elites because they often use policy descriptions that are "short and vague." Bullock finds that the effects of position-taking by party elites on voters' political views are generally smaller than the effects of policy information, and suggests that when people are exposed to both party cues and policy information, the former does not reduce people's attention to the latter: "[i]f anything, they enhance it. To the extent that party cues have large effects in nonexperimental settings, it may be because citizens often know nothing else about the policies and candidates that they are asked to judge" (496-7).

Supporting this position are a number of studies that document the primacy of objective welfare over elite cues. And Prior et al. (2015) show that the evidence of partisan cheer-leading in assessments of the economy declined dramatically with even the most modest monetary incentives to provide an accurate assessment. Writ large, there is healthy skepticism that the importance of elite cues is exaggerated by a reliance on costless survey responses in information-poor contexts.

Our research contributes to this debate by examining the partisan differences in Amer- 
ica's response to the Covid-19 pandemic in the first half of 2020. The outbreak of Covid-19 provides a suitable environment to test the relative power of partisan elite cues and objective information, both of which were discontinuously disseminated in the spring of 2020 . As Covid-19 spread across the United States in the first days of March, public health experts unanimously advocated for individuals to adopt "social distancing" behaviors to reduce the spread of the disease and minimize personal exposure.

These apolitical behaviors carry theoretically heavy welfare costs. Failing to practice social distancing increases not only an individual's personal probability of being infected by a potentially fatal disease, but also the probability of an asymptomatic person infecting others. Conversely, adhering to social distancing guidelines also carries individual costs in the form of foregone wages, reduced consumption, and certain leisure activities.

But as the virus spread, partisan elites in the United States began to send starkly different signals about how their co-partisans should view the risks. President Trump, in particular, was quick to downplay the severity of the disease, declaring in February 2020 that "[i]t's a little like the regular flu that we have flu shots for. And we'll essentially have a flu shot for this in a fairly quick manner"(Trump, 2020a). The President's reassurance was quickly criticized by Democrat officials: "[t]his administration is in complete disarray when it comes to the spread of the coronavirus," senator Chuck Schumer said in a press conference shortly after Trump's remark (Carney, 2020), along with speaker Nancy Pelosi's declaration that "President Trump's delay and denial in responding to the coronavirus pandemic has had 'deadly' consequences for Americans" (Klar, 2020).

What impact did Trump's pronouncements on the severity of the disease have on the way different partisans practice social-distancing during the pandemic? Did the effect of Trump's political cues dominate either countervailing or reinforcing information from the "facts on the ground"? In the following section, we describe the data and methods we employ to measure how Trump's public statements influenced the degree to which residents 
of different counties practiced social distancing.

\section{Data}

To assess behavioral response to the Covid-19 outbreak, we draw data from a mobility measure made publicly available by Cuebiq (2020). Cuebiq collects GPS signals from individuals' smart devices to measure how far users move each day and aggregates it to the county-level for each week. Our analysis uses Cuebiq's county-level data from December 30th, 2019 through May 4th, 2020. We are forced to rely on an aggregated measure of this costly behavior in order to overcome challenges of cheap talk in self-reported survey measures. We argue the value of measuring real behavioral outcomes outweighs the ecological inference issues presented by aggregation (King, Tanner and Rosen, 2004).

Our primary outcome measure is a shelter-in-place (SIP) metric, which captures the percentage of individuals staying at home in any given county. It is defined as a maximum distance traveled of less than 330 feet in any given day, aggregated to a county-week unit of analysis. $^{2}$ We interpret this measure as a proxy for the degree to which residents of different parts of the country adhere to social-distancing behaviors. Figure 1 illustrates the dramatic change in shelter-in-place behaviors that occurred between March 2nd and March 16th, 2020.

Our measure of objective health risks is the spread of confirmed cases of Covid-19 between January 23rd, 2020 and April 13th, 2020, again measured at the county level. These data are obtained from the New York Times (NYT, 2020a) who report daily measures of cases as well as deaths for each county in the U.S., which we then aggregate to the week in order to match to our outcome measures. Our main results predict variation in shelter-inplace behavior as a function of the number of confirmed cases, which we argue is the more

\footnotetext{
${ }^{2}$ We find substantively similar conclusions when replacing our outcome measure with a measure of individual mobility, and summarize these results in Appendix D.
} 

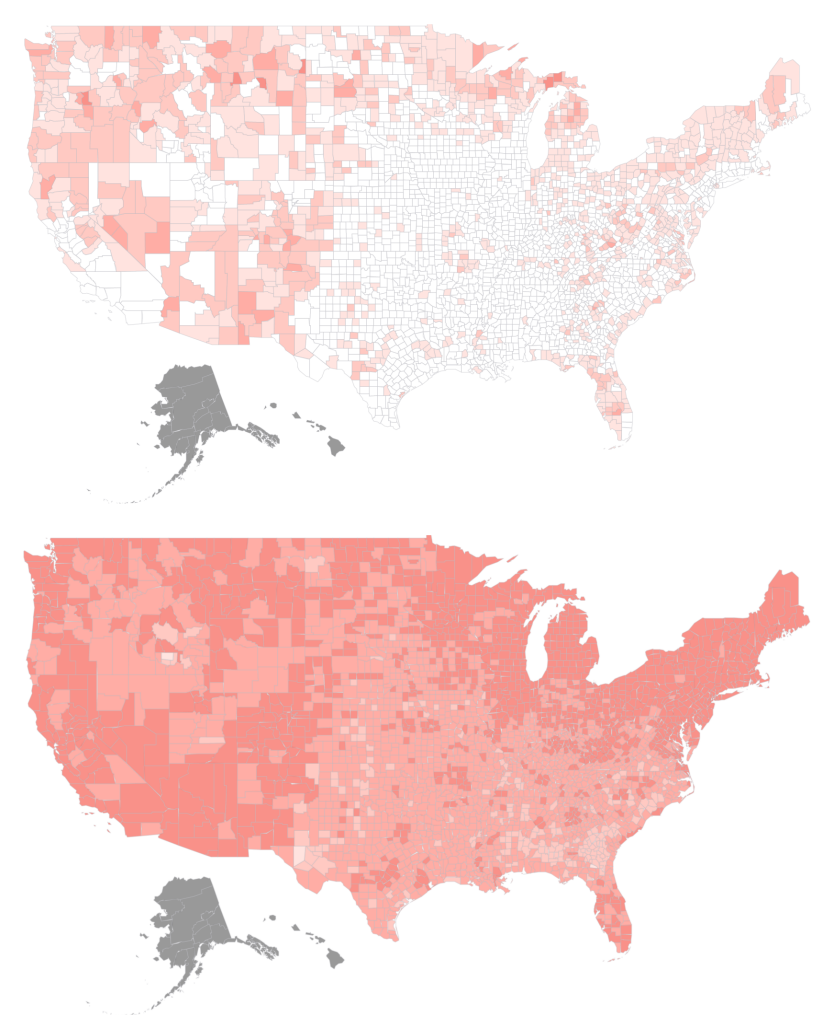

Figure 1: Average number of people sheltering in place by county during the week of March 2nd (top) and March 16th (bottom). Five color shades capture quintiles of the distribution, ranging from the lowest of between 10 to $20 \%$ of the population, to the highest that ranges from 36 to $75 \%$.

salient metric for the information that influences individual behavior. ${ }^{3}$

To construct the competing measure of elite cues, we rely on two sources of data. The first measures party affiliation, using the county-level 2016 presidential election results provided by Townhall.com (2017). We define county-level partisanship based on the twoparty vote shares for Trump and Clinton, respectively.

To measure informational cues generated by partisan elites, we exploit changes in Trump's evaluation of the pandemic revealed in his tweets. Specifically, we scraped Trump's 3,200 most recent tweets covering the period between February 5th and May 20th and manually coded each as either taking the pandemic seriously or downplaying the risks. ${ }^{4}$

\footnotetext{
${ }^{3}$ We confirm our findings are robust to using deaths instead of cases in Appendix D.

${ }^{4}$ See Appendix A for a detailed description of the coding of Trump's tweets.
} 
Figure 2 plots these pronouncements as either positive (i.e., emphasizing the severity of the health risks, referred to as "alarmist" tweets) or negative (i.e., downplaying the severity of the pandemic, referred to as "reassuring" tweets). As depicted in Figure 2, Trump's most alarmist tweets occur in the first weeks of March as the country braced for the outbreak, although we note a constant undercurrent of reassuring cues throughout. We measure the salience of these elite cues as the difference between the alarmist and reassuring tweets, measured as either a raw count per week, the net of total retweets that Trump's tweets received each week, or the net of total favorites ("likes") that Trump's tweets received each week. Our findings are robust to these choices, although we find stronger results when weighting by retweets or favorites, which capture the degree to which these cues were widely shared on Twitter.

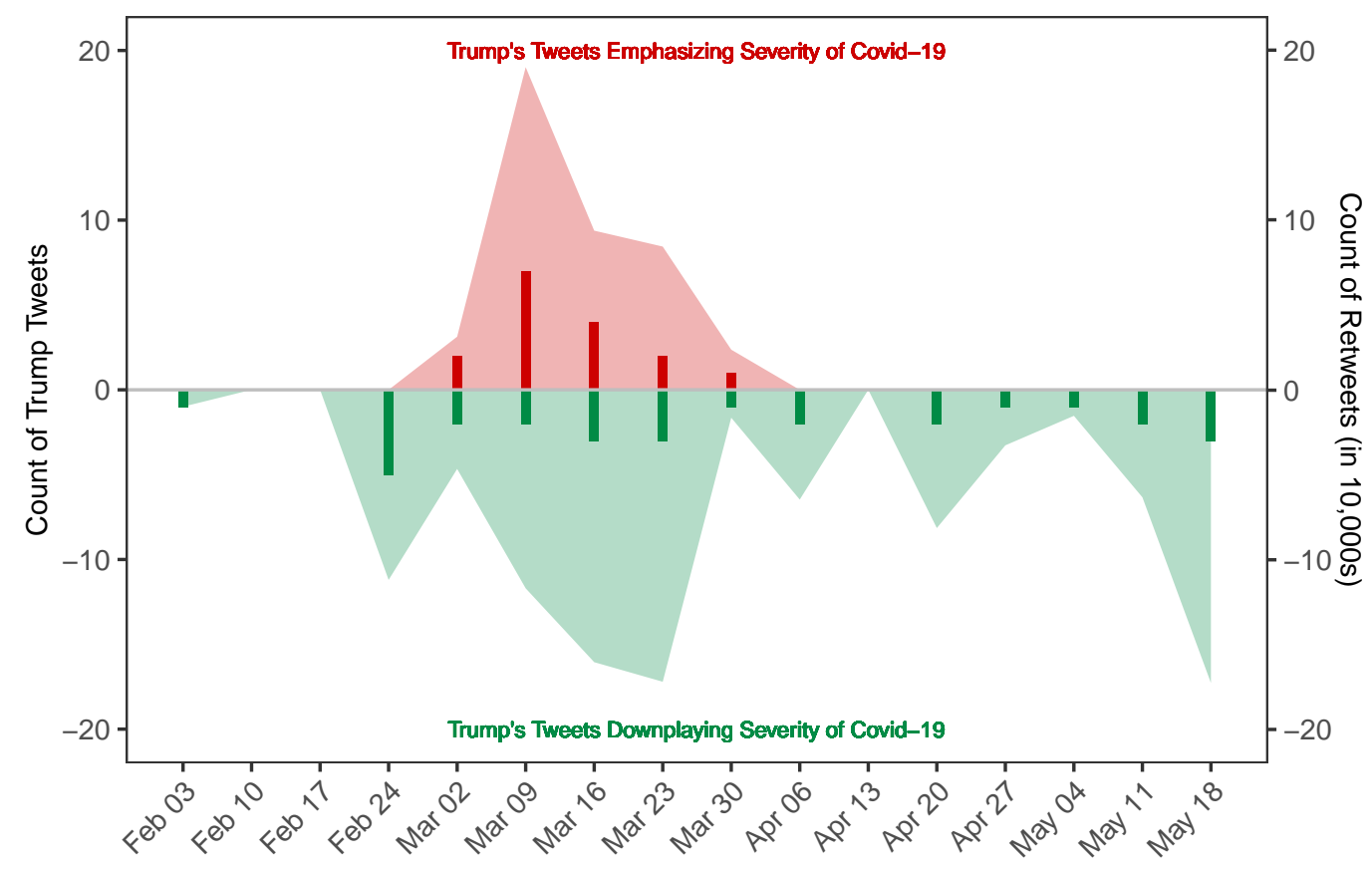

Figure 2: Trump's tweets either taking the pandemic seriously (positive values in red) or downplaying the seriousness (negative values in green). Vertical bars indicate weekly sum of positively and negatively labeled tweets (left axis). Densities indicate the sum of retweets associated with these tweets (right axis).

In order to account for various individual-level characteristics that might confound our 
estimate of partisanship on social-distancing behavior, we gather data on the demographic, economic, and geographical composition for each county. The most notable dimensions are health-related characteristics such as age and pre-existing conditions as well as economicconditions such as income and employment status, which may drastically change one's opportunity cost of sheltering in place. Counties with a large number of senior residents may shelter in place more due to the higher risks of Covid-19 associated with older adults, while counties with a large number of low-income residents may do so less because they simply cannot afford to lose their jobs. In addition to the different risks associated with health and economic conditions, we expect that demographic factors such as race, immigrant status, and education influence an individual's response to the outbreak due to the correlations these characteristics share with partisanship.

We obtain county-specific measures of demographic and geographic characteristics (e.g., population, age, gender, race, and urban residence) from the 5-year American Community Survey of 2013-2017, along with measures of educational attainment. ${ }^{5}$ For countyspecific measures of economic factors (e.g., income and unemployment rate), we gather data from the Quarterly Census of Earnings and Wages for 2019 as well as the Bureau of Labor Statistics for 2019. For an additional health-related factors, we also retrieve county-level life expectancy data from the Centers for Disease Control for 2014.

\section{Methods}

A potential explanation for the observed partisan divide is that the Republican-leaning counties are systematically different from the Democrat-leaning counties in other dimensions, and it is these differences that lead them to respond differently to the pandemic. In Appendix B, we show that Republican-leaning counties have more residents who live in rural areas, receive lower income, are less educated, and are slightly older on average as compared to the

\footnotetext{
${ }^{5}$ Data on county-specific urban and rural residence comes from the 2010 Census.
} 
residents of Democrat-leaning counties. It is also the case that Democratic states imposed state-wide stay-home-orders earlier than Republican states. ${ }^{6}$ Each of these dimensions represents an alternative explanation for why we could observe a weaker response to the outbreak among Republican-leaning counties.

To account for these alternative explanations, and to provide a causally identified "effect" of partisanship, we employ a trajectory balancing method for generalized differencein-differences estimation, developed by Hazlett and Xu (2018). The trajectory balancing method uses kernel-based feature expansion of the pre-treatment outcomes and covariates to provide an approximate balance across treated and control units, the latter of which serve as counterfactuals for the former (Hazlett and $\mathrm{Xu}, 2018$ ). The kernel-based expansion considers the similarity of each unit's trajectory to every other unit's trajectory in multivariate space, and takes this vector of similarities as the features to be balanced. This kernel balancing procedure therefore goes beyond balancing on the average trajectory, ensuring that any function of the pre-treatment outcomes in a large space of smooth functions will have equal means in the treated and control groups (Hazlett and $\mathrm{Xu}, 2018,5$ ). Based on this feature, trajectory balancing reduces the implausibility of the parallel trends assumption that is necessary for standard difference-in-differences estimation strategies. Another advantage of the kernel-based approach is that, by comparing counties that are similar in terms of the outcome of interest prior to the pandemic, we ensure better comparisons across both observed characteristics and any additional factors we are unable to measure but still contribute to the observed outcome behaviors. Trajectory balancing allows us to obtain an estimate of the Average Treatment Effects on the Treated (ATT) by taking the difference between the average of the treated outcomes and the weighted average of control outcomes in the posttreatment period.

\footnotetext{
${ }^{6}$ Democratic states such as California, Illinois, New Jersey, and Washington were among the first states to impose the state-wide restrictions while Republican states such as Oklahoma and Wyoming never had a statewide stay-at-home order.
} 
We appeal to trajectory balancing to assert that we compare Democrat-leaning and Republican-leaning counties that are otherwise similar in terms of both the covariates prior to the pandemic (i.e., race, gender, age, income, unemployment, education, life expectancy, and urbanity) as well as their pre-pandemic shelter-in-place behaviors. This method bolsters our claim that the re-weighted Democrat-leaning counties are valid counterfactuals for the Republican-leaning counties in the post-pandemic period, and that any difference that we observe between the two groups is uniquely attributable to partisanship. We define March 9th as the beginning of the treatment period, due to the discontinuous shift in news coverage of the virus, Trump's declaration of a national state of emergency, the start of state shelterin-place directives, and the decision of many universities to shift to remote learning during this week (NYT, 2020b; Trump, 2020b).

In the subsequent analyses, we drop this single-period definition and instead predict county-level behaviors on county-level cases from the prior week. To adjudicate between the relative influence of elite cues (measured as Trump's tweets) and objective facts (measured as observed cases of Covid-19), we run a linear regression with an interaction term between these two predictors. Specifically, we interact the county's 2016 GOP vote share with a weekly measure of Trump's net communication about the severity of the pandemic, controlling for the number of cases in the preceding week. Formally, for county $c$ in week $t$ :

$$
\mathrm{SIP}_{c, t}=\alpha_{c}+\delta_{t}+\beta_{1} \log (\text { Cases })_{c, t-1}+\beta_{2} \mathrm{GOP}_{16}+\beta_{3} \text { Elite }_{t}+\beta_{4} \mathrm{GOP}_{1} 6_{c} \times \text { Elite }_{t}+\gamma \mathbf{X}_{c}^{\prime}+\varepsilon_{c, t}
$$

where $\log (\text { Cases })_{c, t-1}$ is a logged cumulative cases in county $c$ in the prior week; GOP16 $c$ is Trump's two-party vote share in the 2016 presidential election in county $c ; \mathbf{X}_{c}^{\prime}$ is a vector of pre-pandemic county-level controls. ${ }^{7}$ Importantly, Elite ${ }_{t}$ measures the net sum of alarming and reassuring pronouncements of Trump's tweets on Covid-19, measured either as a raw count, or weighted by the number of times each tweet was either retweeted or favorited. $\alpha_{c}$

\footnotetext{
${ }^{7}$ We also use the mobility indicator as an outcome measure. The results are included in Appendix D.
} 
and $\delta_{t}$ are county and week random effects, respectively, and $\varepsilon_{c, t}$ is a noise parameter. We are interested in $\beta_{4}$ which captures the interactive relationship between a county's partisanship and the degree to which Trump is emphasizing or downplaying the severity of the pandemic.

\section{Results}

We start our analysis with a well-identified test of whether partisanship was truly prognostic of the degree to which different counties adopted social distancing behaviors. We define Republican-leaning counties as those in which Trump received $70 \%$ or more of the two-party vote in 2016. Similarly, we define Democrat-leaning counties as those with $70 \%$ or more vote share for Clinton in the 2016 presidential election. ${ }^{8}$ As shown in Figure 3, trajectory balancing confirms that partisanship exerts an independent effect on the response to the pandemic, even after controlling for the correlated covariates as well as shelter-in-place behaviors prior to the treatment period.

After balancing on the pre-pandemic covariates as well as pre-pandemic shelter-inplace behavior, the difference in weekly mean SIP percentages between Republican-leaning counties with $70 \%$ or more vote share for Trump and Democratic-leaning counties with $70 \%$ or more vote share for Clinton in the 2016 presidential election are almost identical prior to March 9th, but diverge significantly thereafter. Specifically, the gap between the share of Democrat- and Republican-leaning counties that sheltered in place increased from 0.14 percentage points $(\mathrm{S} . \mathrm{E} .=0.048)$ on March 9th, to 6.71 percentage points $(\mathrm{S} . \mathrm{E} .=0.186)$ in the week of May 4th. This indicates that Republican-leaning counties sheltered in place less than Democrat-leaning counties since the beginning of the outbreak, a difference which increasingly diverges over time.

\footnotetext{
${ }^{8}$ The result is similar when we include those moderate counties with less decisive support for one party or the other (i.e., applying $50 \%$ and $60 \%$ cutoffs to define partisanship). See Appendix C for further description.
} 


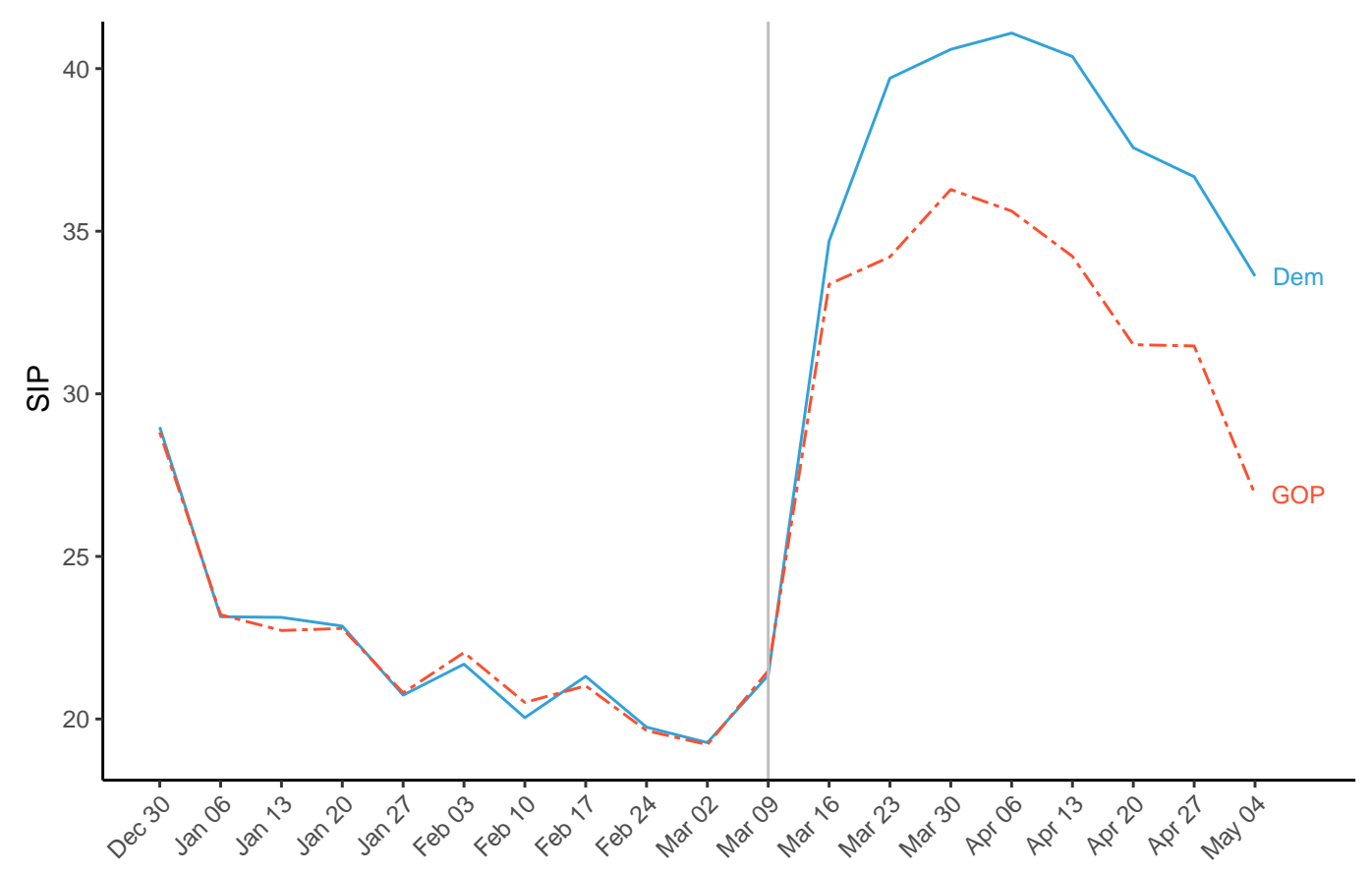

Figure 3: Trajectory counterfactual results. The red line is the average of the (scaled) SIP behavior in counties with $70 \%$ or more vote share for Trump in 2016 . The blue line is the weighted average of the (scaled) SIP behavior in counties with less than $30 \%$ for Trump in 2016. The weights are generated by using kernel expansion on the pre-March 9th outcome measures and matching on the first $k$ moments of the pre-intervention distributions (Hazlett and $\mathrm{Xu}, 2018)$.

The difference in shelter-in-place behaviors between Republican- and Democrat-leaning counties attributable purely to their differences in partisanship is a non-trivial factor in understanding the variation in the response to Covid-19. It is important to highlight, however, that America writ large responded dramatically to Covid-19, with both Democratand Republican-leaning counties dramatically reducing their movement following the week of March 9th. We note that the dynamics of these behaviors also differ over time, with Republican-leaning counties reducing their shelter-in-place behavior from their peak earlier than Democrat-leaning counties. In the next section, we examine the degree to which these differences in behavior following the outbreak are attributable to elite cues. 


\section{Elite Cues}

To examine the relationship between the elite cues embodied in Trump's tweets and the changes in social distancing behavior documented above, we run the interacted regression in Equation 1. Table 1 reports these results. As described above, we operationalize Trump's tweets in three ways. The first two columns report the results using the net count of Trump's tweets as a predictor for elite cues. The next two columns report the results using the net tweets, weighted by the number of retweets that Trump's tweets received each week. Similarly, the last two columns report the results using the net tweets, weighted by the number of favorites that Trump's tweets received each week. The first column within each set of models presents results without the interaction term between partisanship and Trump's tweets, and the second column in each set presents the full results with the interaction.

The results consistently highlight the strong influence that objective facts about the spread of the pandemic have on counties' social distancing behavior. The coefficient on logged number of cases are positive for all models, indicating that counties that experience a relatively higher number of Covid-19 cases shelter in place more on average, all else equal. Substantively, the estimated coefficients suggest that a standard deviation increase in the logged number of cases - approximately six new cases in the preceding week in a county corresponds to a roughly 1.3 percentage point increase in the share of residents sheltering in place in a given county.

These findings provide tentative support to the argument that the objective information about the pandemic may matter more than partisan cues on counties' social distancing behavior. However, we also note that the coefficient on the GOP vote share variable is larger than that of the logged cases, suggesting an important role to be played by partisanship.

In assessing the marginal influence of the partisan elite cues, the interaction terms in

Table 1 provide evidence consistent with the idea that elite cues influence the behavior of 
Table 1: SIP as a Function of Partisanship and Trump's Tweets

\begin{tabular}{|c|c|c|c|c|c|c|}
\hline & \multicolumn{6}{|c|}{ Dependent variable: SIP } \\
\hline & \multicolumn{2}{|c|}{ Tweets, Net } & \multicolumn{2}{|c|}{ Retweets, Net } & \multicolumn{2}{|c|}{ Favorites, Net } \\
\hline & $(1)$ & $(2)$ & $(3)$ & $(4)$ & $(5)$ & $(6)$ \\
\hline GOP Vote Share & $\begin{array}{c}-0.25^{* * *} \\
(0.01)\end{array}$ & $\begin{array}{c}-0.25^{* * *} \\
(0.01)\end{array}$ & $\begin{array}{c}-0.25^{* * *} \\
(0.01)\end{array}$ & $\begin{array}{c}-0.24^{* * *} \\
(0.01)\end{array}$ & $\begin{array}{c}-0.25^{* * *} \\
(0.01)\end{array}$ & $\begin{array}{c}-0.24^{* * *} \\
(0.01)\end{array}$ \\
\hline Trump's Tweets & $\begin{array}{l}-0.28 \\
(0.20)\end{array}$ & $\begin{array}{l}-0.30 \\
(0.20)\end{array}$ & $\begin{array}{c}-0.33^{*} \\
(0.18)\end{array}$ & $\begin{array}{c}-0.33^{*} \\
(0.18)\end{array}$ & $\begin{array}{l}-0.28 \\
(0.17)\end{array}$ & $\begin{array}{l}-0.28 \\
(0.17)\end{array}$ \\
\hline GOP X Trump's Tweets & & $\begin{array}{c}0.06^{* * *} \\
(0.001)\end{array}$ & & $\begin{array}{c}0.05^{* * *} \\
(0.001)\end{array}$ & & $\begin{array}{c}0.04^{* * *} \\
(0.001)\end{array}$ \\
\hline $\log$ (Cases) & $\begin{array}{c}0.17^{* * *} \\
(0.002)\end{array}$ & $\begin{array}{c}0.15^{* * *} \\
(0.002)\end{array}$ & $\begin{array}{c}0.17^{* * *} \\
(0.002)\end{array}$ & $\begin{array}{c}0.16^{* * *} \\
(0.002)\end{array}$ & $\begin{array}{c}0.17^{* * *} \\
(0.002)\end{array}$ & $\begin{array}{c}0.15^{* * *} \\
(0.002)\end{array}$ \\
\hline $\log$ (Population) & $\begin{array}{c}-0.03^{* * *} \\
(0.01)\end{array}$ & $\begin{array}{c}-0.02^{* *} \\
(0.01)\end{array}$ & $\begin{array}{c}-0.03^{* * *} \\
(0.01)\end{array}$ & $\begin{array}{c}-0.02^{* * *} \\
(0.01)\end{array}$ & $\begin{array}{c}-0.03^{* * *} \\
(0.01)\end{array}$ & $\begin{array}{c}-0.02^{\text {*** }} \\
(0.01)\end{array}$ \\
\hline Female, \% & $\begin{array}{c}-0.04^{* * *} \\
(0.01)\end{array}$ & $\begin{array}{c}-0.04^{* * *} \\
(0.01)\end{array}$ & $\begin{array}{c}-0.04^{* * *} \\
(0.01)\end{array}$ & $\begin{array}{c}-0.04^{* * *} \\
(0.01)\end{array}$ & $\begin{array}{c}-0.04^{* * *} \\
(0.01)\end{array}$ & $\begin{array}{c}-0.04^{* * *} \\
(0.01)\end{array}$ \\
\hline Black, \% & $\begin{array}{c}-0.22^{* * *} \\
(0.01)\end{array}$ & $\begin{array}{c}-0.22^{* * *} \\
(0.01)\end{array}$ & $\begin{array}{c}-0.22^{* * *} \\
(0.01)\end{array}$ & $\begin{array}{c}-0.22^{* * *} \\
(0.01)\end{array}$ & $\begin{array}{c}-0.22^{* * *} \\
(0.01)\end{array}$ & $\begin{array}{c}-0.22^{* * *} \\
(0.01)\end{array}$ \\
\hline Hispanic, \% & $\begin{array}{c}-0.07^{* * *} \\
(0.01)\end{array}$ & $\begin{array}{c}-0.07^{* * *} \\
(0.01)\end{array}$ & $\begin{array}{c}-0.07^{* * *} \\
(0.01)\end{array}$ & $\begin{array}{c}-0.07^{* * *} \\
(0.01)\end{array}$ & $\begin{array}{c}-0.07^{* * *} \\
(0.01)\end{array}$ & $\begin{array}{c}-0.07^{* * *} \\
(0.01)\end{array}$ \\
\hline Age $<=19, \%$ & $\begin{array}{c}-0.05^{* * *} \\
(0.01)\end{array}$ & $\begin{array}{c}-0.05^{* * *} \\
(0.01)\end{array}$ & $\begin{array}{c}-0.05^{* * *} \\
(0.01)\end{array}$ & $\begin{array}{c}-0.05^{* * *} \\
(0.01)\end{array}$ & $\begin{array}{c}-0.05^{* * *} \\
(0.01)\end{array}$ & $\begin{array}{c}-0.05^{* * *} \\
(0.01)\end{array}$ \\
\hline Age $>=50, \%$ & $\begin{array}{c}0.09^{* * *} \\
(0.01)\end{array}$ & $\begin{array}{c}0.09^{* * *} \\
(0.01)\end{array}$ & $\begin{array}{c}0.09^{* * *} \\
(0.01)\end{array}$ & $\begin{array}{c}0.09^{* * *} \\
(0.01)\end{array}$ & $\begin{array}{c}0.09^{* * *} \\
(0.01)\end{array}$ & $\begin{array}{c}0.09^{* * *} \\
(0.01)\end{array}$ \\
\hline Income & $\begin{array}{c}0.08^{* * *} \\
(0.01)\end{array}$ & $\begin{array}{c}0.08^{* * *} \\
(0.01)\end{array}$ & $\begin{array}{c}0.08^{* * *} \\
(0.01)\end{array}$ & $\begin{array}{c}0.08^{* * *} \\
(0.01)\end{array}$ & $\begin{array}{c}0.08^{* * *} \\
(0.01)\end{array}$ & $\begin{array}{c}0.08^{* * *} \\
(0.01)\end{array}$ \\
\hline Unemp. Rate & $\begin{array}{c}0.12^{* * *} \\
(0.01)\end{array}$ & $\begin{array}{c}0.12^{* * *} \\
(0.01)\end{array}$ & $\begin{array}{c}0.12^{* * *} \\
(0.01)\end{array}$ & $\begin{array}{c}0.12^{* * *} \\
(0.01)\end{array}$ & $\begin{array}{c}0.12^{* * *} \\
(0.01)\end{array}$ & $\begin{array}{c}0.12^{* * *} \\
(0.01)\end{array}$ \\
\hline Educ: HS, \% & $\begin{array}{c}-0.03^{*} \\
(0.02)\end{array}$ & $\begin{array}{c}-0.04^{* *} \\
(0.02)\end{array}$ & $\begin{array}{c}-0.03^{*} \\
(0.02)\end{array}$ & $\begin{array}{c}-0.03^{* *} \\
(0.02)\end{array}$ & $\begin{array}{c}-0.03^{*} \\
(0.02)\end{array}$ & $\begin{array}{c}-0.03^{* *} \\
(0.02)\end{array}$ \\
\hline Educ: Bachelor's, \% & $\begin{array}{c}0.03 \\
(0.02)\end{array}$ & $\begin{array}{l}0.03^{* *} \\
(0.02)\end{array}$ & $\begin{array}{c}0.03 \\
(0.02)\end{array}$ & $\begin{array}{l}0.03^{*} \\
(0.02)\end{array}$ & $\begin{array}{c}0.03 \\
(0.02)\end{array}$ & $\begin{array}{l}0.03^{*} \\
(0.02)\end{array}$ \\
\hline Rural Residence, \% & $\begin{array}{c}-0.02^{* *} \\
(0.01)\end{array}$ & $\begin{array}{c}-0.02^{* *} \\
(0.01)\end{array}$ & $\begin{array}{c}-0.02^{* *} \\
(0.01)\end{array}$ & $\begin{array}{c}-0.02^{* *} \\
(0.01)\end{array}$ & $\begin{array}{c}-0.02^{* *} \\
(0.01)\end{array}$ & $\begin{array}{c}-0.02^{* *} \\
(0.01)\end{array}$ \\
\hline Life Expectancy & $\begin{array}{c}0.13^{* * *} \\
(0.01)\end{array}$ & $\begin{array}{c}0.13^{* * *} \\
(0.01)\end{array}$ & $\begin{array}{c}0.13^{* * *} \\
(0.01)\end{array}$ & $\begin{array}{c}0.13^{* * *} \\
(0.01)\end{array}$ & $\begin{array}{c}0.13^{* * *} \\
(0.01)\end{array}$ & $\begin{array}{c}0.13^{* * *} \\
(0.01)\end{array}$ \\
\hline Constant & $\begin{array}{c}0.63^{* * *} \\
(0.23)\end{array}$ & $\begin{array}{c}0.52^{* *} \\
(0.23)\end{array}$ & $\begin{array}{c}0.53^{* *} \\
(0.22)\end{array}$ & $\begin{array}{c}0.48^{* *} \\
(0.22)\end{array}$ & $\begin{array}{l}0.55^{* *} \\
(0.22)\end{array}$ & $\begin{array}{c}0.48^{* *} \\
(0.22)\end{array}$ \\
\hline Observations & 31,080 & 31,080 & 31,080 & 31,080 & 31,080 & 31,080 \\
\hline Log Likelihood & $-7,357.65$ & $-6,483.58$ & $-7,357.20$ & $-6,704.12$ & $-7,357.53$ & $-6,726.75$ \\
\hline County RE & $\mathrm{Y}$ & Y & Y & $\mathrm{Y}$ & $\mathrm{Y}$ & Y \\
\hline Week RE & Y & Y & Y & Y & $\mathrm{Y}$ & $\mathrm{Y}$ \\
\hline
\end{tabular}

Note: ${ }^{*} \mathrm{p}<0.1 ;{ }^{* *} \mathrm{p}<0.05 ;{ }^{* * *} \mathrm{p}<0.01$. All non-logged variables are scaled. 
partisans. As depicted in column 1, support for Trump is negatively correlated with social distancing behavior, reducing SIP by approximately one-quarter of a standard deviation, or roughly 2.14 percentage points fewer people sheltering in place per a 15.61 percentage point increase in support for Trump in 2016. This measure also comports with the overall average difference documented in the trajectory balancing results summarized above, where moving from $30 \%$ for Trump to $70 \%$ for Trump was estimated to produce a 6.71 percentage point difference in the share of residents sheltering in place in a given county.
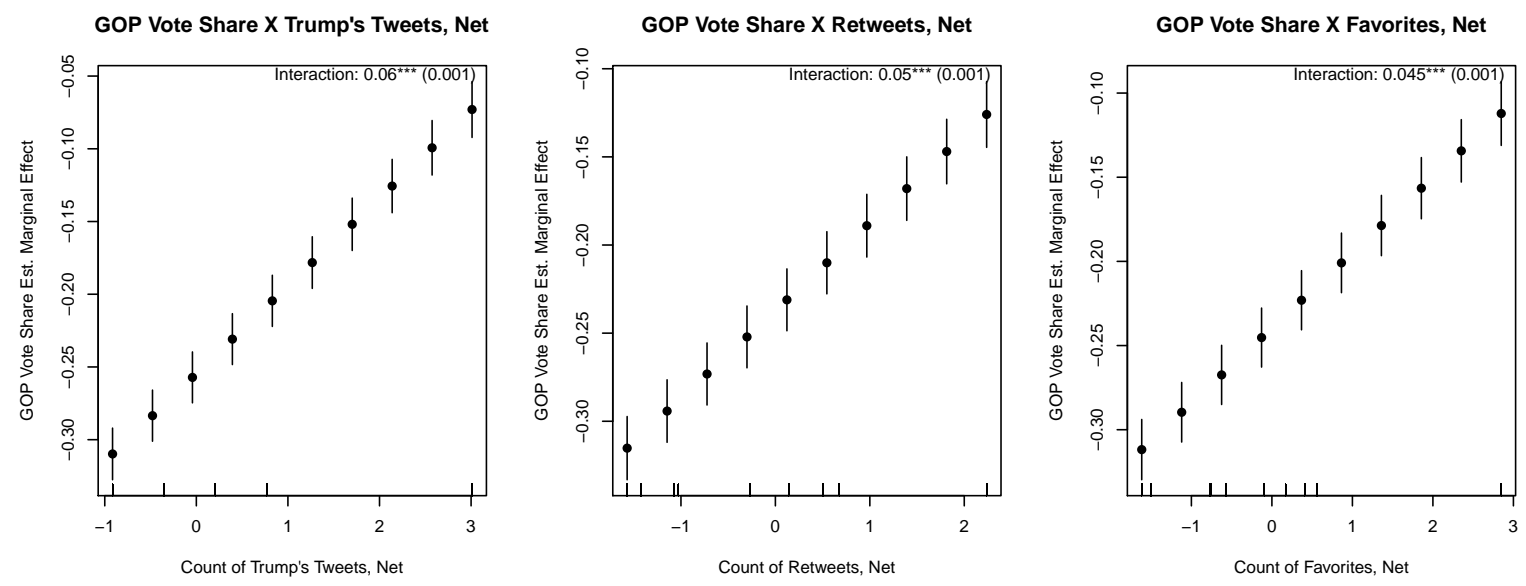

Figure 4: Marginal effects plots for raw tweets (left column), retweets (center column), and favorited tweets (right column), estimated using a multilevel model with county and week random effects. Regressions estimated using scaled measures of the outcome and explanatory variables to facilitate comparison.

We visualize these interaction estimates with marginal effects plots in Figure 4. This figure displays the marginal relationship between the county's 2016 support for Trump and its shelter-in-place behavior across variation in Trump's net message on the severity of the pandemic, measured as the difference in the raw count of alarmist and downplaying tweets (left panel), the same difference weighted by the number of times each message was retweeted (middle panel), and the same difference again, weighted by the number of times each message received "likes" (right panel). As illustrated, the gap between the share of Democratand Republican-leaning counties that shelter-in-place shrinks when Trump emphasizes the severity of the pandemic. A one standard deviation increase in Trump's net tweets (i.e., 
when Trump's tweets are relatively more alarming of the disease) reduces the gap between Democrat- and Republican-leaning counties' SIP behavior by 0.06 standard deviations. Put another way, moving from the week in which Trump's tweets are most reassuring to the week in which he is at his most alarmist reduces the negative marginal effect of GOP vote share by almost $23 \%$.

To give an idea of when this variation happens, we overlay the plot of trajectory balanced averages of SIP by partisan counties with Trump's alarming as well as downplaying tweets, weighted by the number of favorites received (see Figure 5). While both Republicanand Democrat-leaning counties responded in a similar fashion to the state of emergency during the week of March 9th, Republican-leaning counties increased their shelter-in-place practice by only a little between the weeks of March 16th and 23rd, while Democrat-leaning counties continued to dramatically increase sheltering in place during the same period. This attenuated response by the Republican-leaning counties corresponds to a shift in Trump's messages regarding Covid-19, moving from alarmist cues in the week of March 9th, to downplaying the severity between March 16th and March 23rd. However, Republican-leaning counties increased their shelter-in-place behavior by more than Democrat-leaning counties between March 23rd and March 30th, the period during which the net message from their copartisan president was more alarmist. This is consistent with our estimates that Republicanleaning counties shelter in place more when Trump raises the alarm, and less when Trump downplays the severity of the disease. Taken together, our empirical analysis strongly suggests that temporal variation in the degree to which Democrat- and Republican-leaning counties diverged in their shelter-in-place behaviors is correlated with the degree to which Trump did or did not take the risks seriously. 


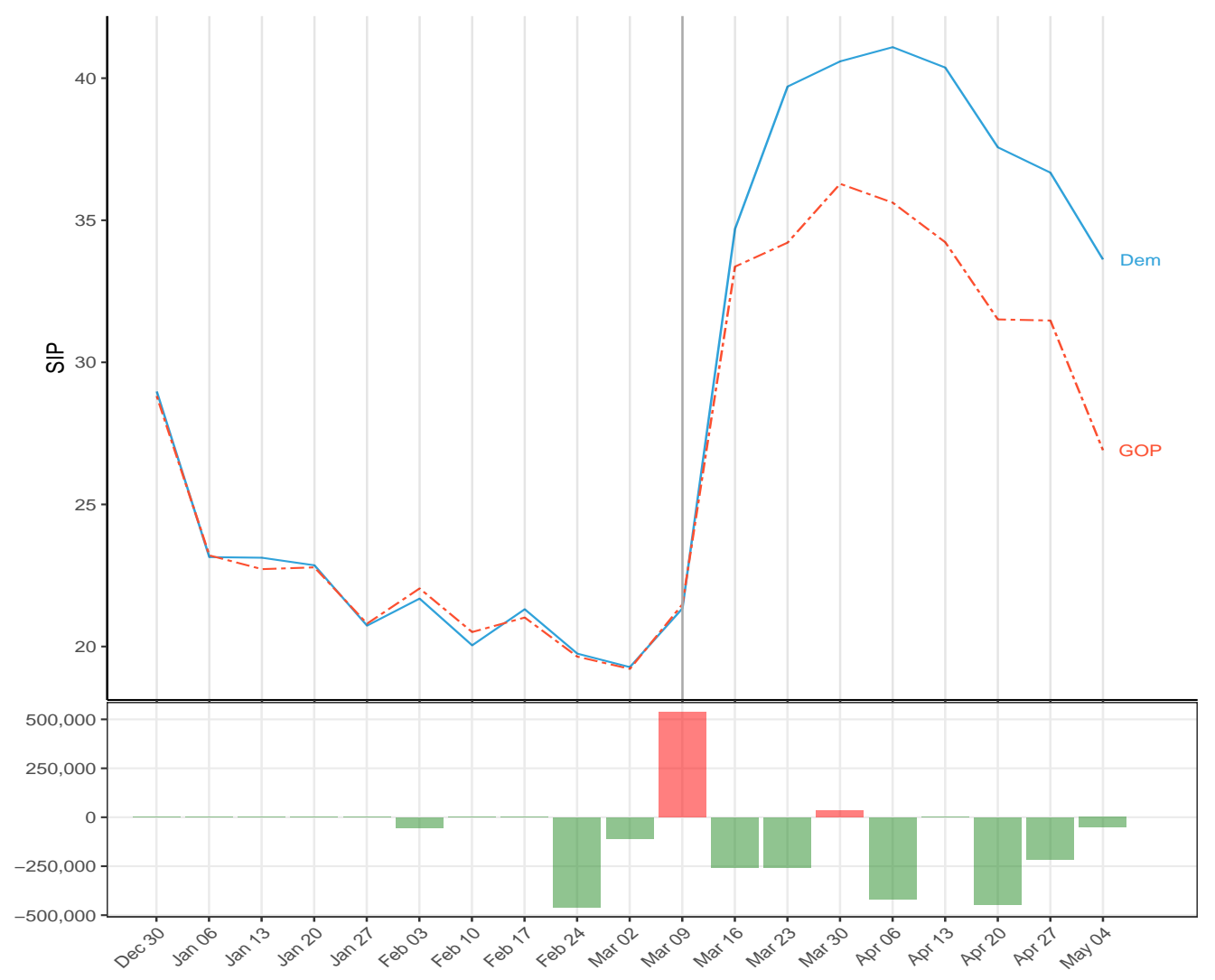

Figure 5: Trajectory balancing results (top panel) overlaid with the net cues embodied in Trump's tweets, weighted by the total number of favorites the tweets received (bottom panel).

\section{Elite Cues vs. Objective Information}

The preceding results focus on the difference between Democrat- and Republican-leaning counties across different periods of Trump's cues, controlling for the number of Covid-19 cases in a given county. The findings suggest a statistically and substantively meaningful difference between Democrat- and Republican-leaning counties, and argue that part of this difference is due to the elite cues sent by President Trump. However, we have also shown that the country writ large dramatically adjusted its behavior after the week starting March 9th, suggesting that even the most heavily Republican counties responded to Covid-19 by sheltering in place. This is also evident in our model in Table 1 that shows consistently positive relationship between the logged number of cases and counties' shelter-in-place behavior. 
The findings summarized thus far suggest that both elite cues and objective facts are important predictors of social distancing behaviors. But which of these dominates? Does the number of local cases matter more to the share of residents that shelter in place in a given county? Or is the social distancing behavior ultimately determined by partisanship and elite cues?

We evaluate this question by moving beyond coefficient estimates and marginal effects, and instead examine the variable importance of these competing measures. Specifically, we assess the penalty in the predictive accuracy of a non-parametric regression model when we break the observed relationship between the outcome measure and a given explanatory variable. To put it more concretely, we compare the root mean square error (RMSE) of a random forest trained on the observed data with the RMSE generated by the same model in which the logged number of cases (for example) are randomly shuffled. The difference between these two measures of predictive accuracy is saved as a multiplier on the RMSE, capturing the percent change in model performance due to breaking the empirical relationship between an outcome and a given predictor. This type of evaluation is referred to as a permutation test in the machine learning literature, and is shown to outperform other measures of variable importance that utilizes random forests (Breiman, 2001). ${ }^{9}$

Figure 6 plots the variable importance metric estimated on 500 bootstrapped samples of our data. Rather than performing the variable importance analysis on the entirety of the data, we bootstrap 500 times in order to make inferential statements about whether these variables differ significantly in terms of importance. As illustrated in Figure 6, the level of importance is strikingly high for the logged number of cases in a given county, followed by

\footnotetext{
${ }^{9} \mathrm{~A}$ downside to this approach is that we cannot directly assess coefficient magnitudes or signs. In Appendix E, we confirm the robustness of the results to an alternative LASSO regression method, which allows us to estimate both the direction and magnitude of the estimated coefficients in addition to the level of importance.
} 
Trump's tweets, weighted by the number of retweets each status received. ${ }^{10}$

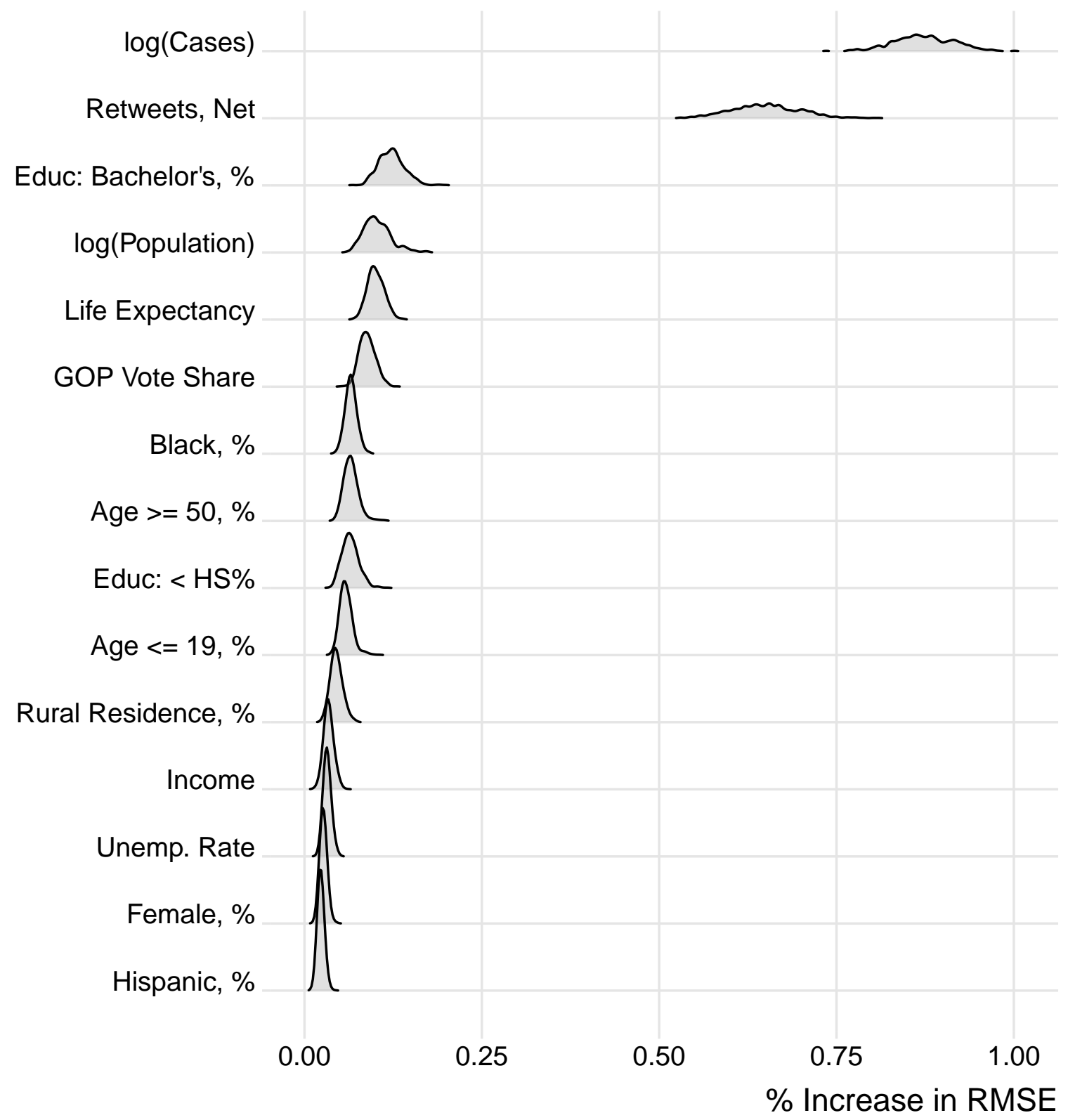

Figure 6: Variable importance measures (x-axis) for predictors given on y-axis. Densities reflect 500 bootstrapped samples of the data.

${ }^{10}$ The result is similar when we scale Trump's tweets by the number of favorites instead of retweets. We add indicators for the week and county in Appendix E, confirming that the substantive conclusions are robust to their inclusion. We omit them in our main analysis because weeks are highly correlated with both cases and tweets. This correlation allows the model to perform better when either of these measures are dropped, resulting in weaker evidence of their importance to prediction. 
These results suggest two crucial caveats to the evidence of the partisan divide in the county-level response to the pandemic discussed above. First, shelter-in-place behaviors are influenced most strongly by the spread of the pandemic itself, with variation in logged cases over both place and time emerging as the most important predictor. Second, Trump's tweets are the second most important predictor in our model, but the relative influence of the partisan make-up of a county is much lower. Specifically, the 2016 Republican presidential election vote share of a given county is less important than the county's demographic factors such as total population, life expectancy, and the share of county population with a bachelor's degree or above. Permuting this predictor results in less than a $15 \%$ increase in the root mean squared error. In sum, the variable importance measures suggest that objective facts and the President's opinion leadership far outweigh the partisan make-up of a county.

However, these are based on the data in aggregate. To examine the interplay between elite cues and partisanship, we again divide the counties according to their 2016 presidential voting behavior and re-estimate these variable importance measures on subsets of the data. For the densities displayed in Figure 7, we define Democrat-leaning counties as those with $70 \%$ or more vote share for Clinton in 2016 presidential election, and Republican-leaning counties as those with $70 \%$ or more vote share for Trump. To make an apples-to-apples comparison, we re-scale the variable importance for each bootstrap simulation to be between zero and one, allowing us to compare the rank order and magnitude between the two groups of counties. As illustrated, the importance of Trump's tweets on predicting shelter-inplace behaviors is greater among Republican-leaning counties relative to Democrat-leaning counties, to the extent that it is the most important predictor in the majority of bootstrap simulations. Conversely, while Trump's tweets are also important in Democrat-leaning counties, they are only half as important as the actual Covid-19 cases. These results highlight the differential importance of elite communication between co-partisans and out-partisans. 


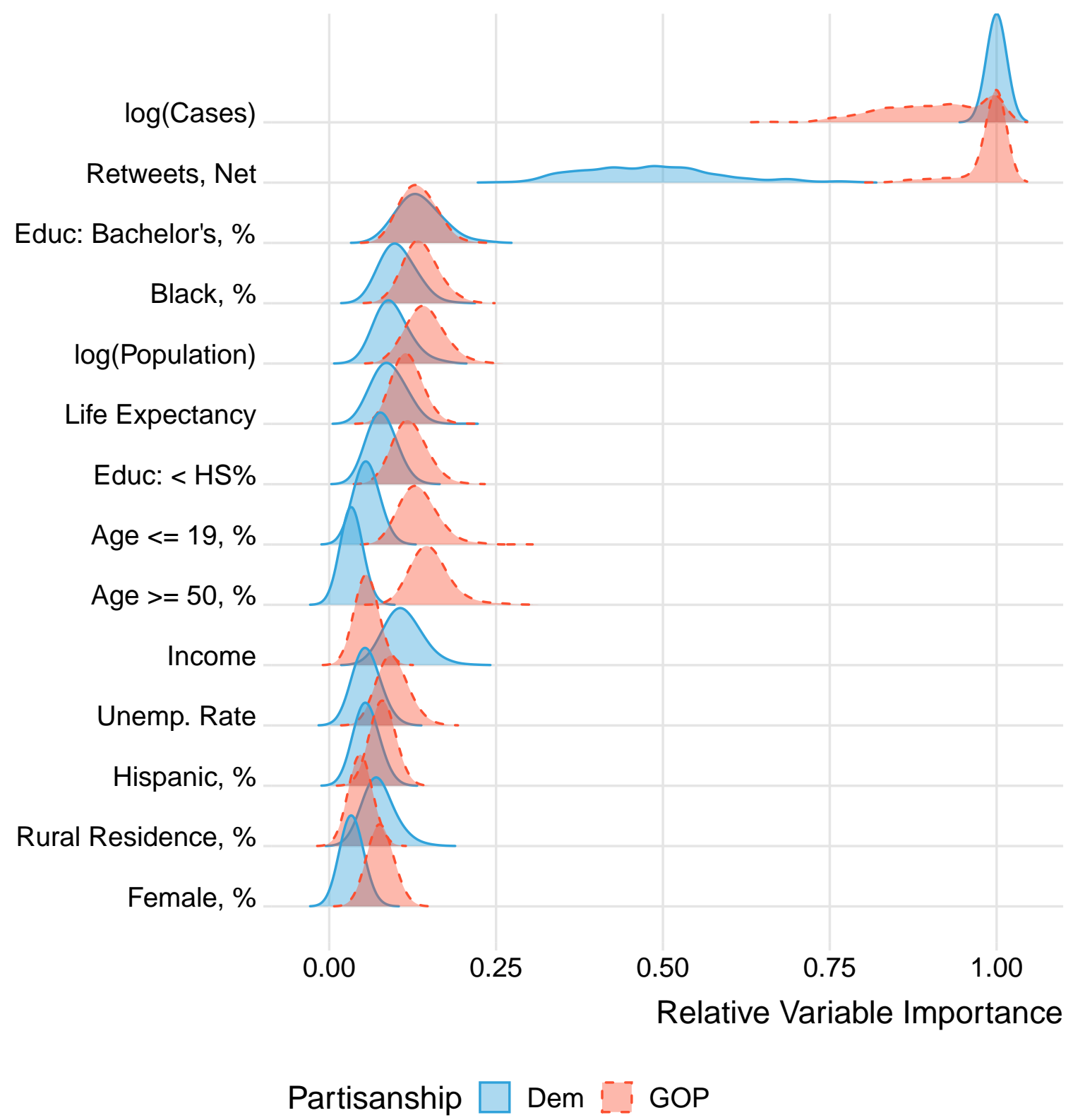

Figure 7: Relative variable importance measures (x-axis) for predictors given on y-axis. Densities reflect 500 bootstrapped samples of the data.

\section{Discussion}

Many scholars argue that citizens mechanically adopt the policy preferences of their party leaders even when they have other information on which to base their judgments (Cohen, 2003; Iyengar and Valentino, 2000; Lenz, 2012; Rahn, 1993; Zaller, 1992). However, such 
preferences rarely have immediate or direct effects on an individual's welfare. In this paper, we examine whether partisan elite cues influence non-political behaviors that carry real welfare costs. Using county-level measures of costly social distancing behaviors and objective measures of health threats, we find evidence that counties responded dramatically to the spread of Covid-19. Yet we also document a large gap in this response between Democraticleaning counties and Republican-leaning counties. By weighting Democrat-leaning counties to more closely resemble Republican-leaning counties in the pre-pandemic period, we isolate the part of this gap that is due solely to partisanship and find that the share of residents of Republican-leaning counties who sheltered in place was roughly 5 percentage points lower than the share in otherwise similar Democrat-leaning counties between March 9th and May 4th. Furthermore, we connect a county's weekly variation in social distancing behavior to elite cues about the severity of the pandemic, measured with President Trump's tweets that either downplayed or emphasized the severity of the pandemic. We find that residents of Republican-leaning counties shelter in place more in weeks when Trump accentuates the risks associated with the coronavirus and less in weeks when Trump downplays the risks.

These results reveal an important role played by partisanship and elite cues, even in contexts where the behaviors of interest are decidedly not "cheap talk". Nevertheless, partisanship is not driving the bus entirely. Using permutation tests for variable importance, we find that the logged number of Covid-19 cases is the most important predictor of shelterin-place behaviors in general. But this conclusion changes when we subset the counties by partisanship. The spread of the pandemic remains the most important predictor among Democrat-leaning counties, while Trump's tweets are more important than the number of cases among Republican-leaning counties.

While informative, there is a great deal that our analysis does not tell us. We do not know whether this is an information story in which people are exposed to different messages, or whether this is a motivated reasoning story in which people, even when they receive 
messages from both parties, choose to believe cues from their co-partisan elites over those issued by out-partisan elites. Our evidence also does not speak to the role of other political leaders. The president's public statements (measured in Tweets) is one of many elite cues being transmitted to the public. As Zaller (1992) notes, in a message environment in which elites disagree, the pattern of public opinion will depend on the nature of the dominant message flow at a given point in time. While Trump's message has a way of dominating the political debate - and indeed the degree to which his tweets alone are covered by the mass media is well-documented - his pronouncements get both amplified by other Republican politicians and counterbalanced by Democrat politicians, all of which interact in a way that the President's tweets alone are unable to capture. Further studies should examine how citizens digest diverse elite cues being sent by different political elites.

With these important caveats aside, we believe that these results contribute to our understanding of the interplay between objective reality and partisan cues in two ways. First, we show that partisan-motivated reasoning is not limited to costless survey responses. Indeed, even in matters of literal life and death, the power of party affiliation persists.

Second, we shed light on the magnitude and mechanisms of the differential response to Covid-19 in the United States. Specifically, we show that both Democrat- and Republicanleaning counties responded dramatically to the outbreak and to the requests by experts, federal and state government, and society itself to mitigate the health risks by reducing physical movement. Yet we also show that the difference in the degree of this response is at least partly attributable to elite cues, providing evidence of the welfare risks associated with partisanship. 


\section{References}

Abramowitz, Alan I. 1978. "The impact of a presidential debate on voter rationality." American Journal of Political Science pp. 680-690.

Achen, Christopher H and Larry M Bartels. 2016. Democracy for realists: Why elections do not produce responsive government. Vol. 4 Princeton University Press.

Berelson, Bernard, Hazel Gaudet and Paul F Lazarsfeld. 1968. The people's choice: How the voter makes up his mind in a presidential campaign. Columbia University Press.

Berelson, Bernard R, Paul F Lazarsfeld and William N McPhee. 1954. Voting: A study of opinion formation in a presidential campaign. University of Chicago Press.

Bisgaard, Martin. 2015. "Bias will find a way: Economic perceptions, attributions of blame, and partisan-motivated reasoning during crisis." The Journal of Politics 77(3):849-860.

Breiman, Leo. 2001. "Random forests." Machine learning 45(1):5-32.

Broockman, David E and Daniel M Butler. 2017. "The Causal Effects of Elite PositionTaking on Voter Attitudes: Field Experiments with Elite Communication." American Journal of Political Science 61(1):208-221.

Bullock, John G. 2011. "Elite influence on public opinion in an informed electorate." American Political Science Review pp. 496-515.

Bullock, John G, Alan S Gerber, Seth J Hill and Gregory A Huber. 2013. Partisan bias in factual beliefs about politics. Technical report National Bureau of Economic Research.

Cacioppo, John T and Richard E Petty. 1984. "The elaboration likelihood model of persuasion." ACR North American Advances .

Campbell, Angus, Philip E Converse, Warren E Miller and Donald E Stokes. 1960. The american voter. University of Chicago Press. 
Carney, Jordain. 2020. "Schumer: Trump coronavirus response marked by 'towering and dangerous incompetence'." The Hill .

URL: $\quad$ https:/thehill.com/homenews/senate/484548-schumer-trump-coronavirusresponse-marked-by-towering-and-dangerous

Carsey, Thomas M and Geoffrey C Layman. 2006. "Changing sides or changing minds? Party identification and policy preferences in the American electorate." American Journal of Political Science 50(2):464-477.

Cavaillé, Charlotte, Daniel L Chen and Karine Van der Straeten. 2020. "Who Cares? Measuring Preference Intensity in a Polarized Environment.".

Chen, Jowei. 2013. "Voter partisanship and the effect of distributive spending on political participation." American Journal of Political Science 57(1):200-217.

Cohen, Geoffrey L. 2003. "Party over policy: The dominating impact of group influence on political beliefs." Journal of personality and social psychology 85(5):808.

Cuebiq. 2020. "COVID-19 Mobility Insights.".

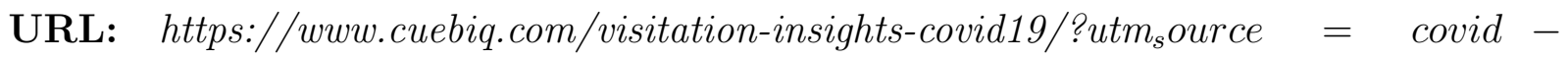
outreachutm $_{m}$ edium $=$ homepage - bannerutm $_{c}$ ampaign $=$ covid $-19-$ insights outreach -2020

Downs, Anthony. 1957. "An economic theory of democracy.".

Hazlett, Chad and Yiqing Xu. 2018. "Trajectory balancing: A general reweighting approach to causal inference with time-series cross-sectional data." Available at SSRN 3214231.

Hetherington, Marc J. 2001. "Resurgent mass partisanship: The role of elite polarization." American Political Science Review 95(3):619-631.

Iyengar, Shanto and Nicholas A Valentino. 2000. "Who Says What? Source Credibility as a 
Mediator of Campaign Effects." Elements of Reason: Cognition, Choice, and the Bounds of Rationality .

King, Gary, Martin A Tanner and Ori Rosen. 2004. Ecological inference: New methodological strategies. Cambridge University Press.

Klar, Rebecca. 2020. "Pelosi: Trump's denial, delay on coronavirus response 'is deadly'." The Hill .

URL: ｈttps://thehill.com/homenews/house/490043-pelosi-trumps-denial-delay-oncoronavirus-response-is-deadly

Kruglanski, Arie W and Donna M Webster. 1996. "Motivated closing of the mind:" Seizing" and" freezing."." Psychological review 103(2):263.

Kunda, Ziva. 1990. "The case for motivated reasoning." Psychological bulletin 108(3):480.

Lenz, Gabriel S. 2012. "Follow the Leader?: How Voters Respond to Politicians' Policies and Performance.".

Lodge, Milton and Charles S Taber. 2006. "Motivated skepticism in the evaluation of political beliefs." American journal of political science 50(3):755-769.

Lodge, Milton and Charles S Taber. 2013. The rationalizing voter. Cambridge University Press.

Mackie, Diane and Joel Cooper. 1984. "Attitude polarization: Effects of group membership." Journal of Personality and Social Psychology 46(3):575.

McGuire, W. 1969. "The nature of attitudes and attitude change. Vol. 3.".

Miller, Joanne M, Kyle L Saunders and Christina E Farhart. 2016. "Conspiracy endorsement as motivated reasoning: The moderating roles of political knowledge and trust." American Journal of Political Science 60(4):824-844. 
Minozzi, William, Michael A Neblo, Kevin M Esterling and David MJ Lazer. 2015. "Field experiment evidence of substantive, attributional, and behavioral persuasion by members of Congress in online town halls." Proceedings of the National Academy of Sciences 112(13):3937-3942.

NYT. 2020a. "nytimes/covid-19-data.".

URL: https://github.com/nytimes/covid-19-data

NYT. 2020b. "See Which States and Cities Have Told Residents to Stay at Home.". URL: $\quad$ https://www.nytimes.com/interactive/2020/us/coronavirus-stay-at-homeorder.html

Popkin, Samuel L. 1994. The Reasoning Voter: Communication and Persuasion in Presidential Campaigns. 2 ed. Chicago: Chicago University Press.

Prior, Markus, Gaurav Sood, Kabir Khanna et al. 2015. "You cannot be serious: The impact of accuracy incentives on partisan bias in reports of economic perceptions." Quarterly Journal of Political Science 10(4):489-518.

Rahn, Wendy M. 1993. "The role of partisan stereotypes in information processing about political candidates." American Journal of Political Science pp. 472-496.

Townhall.com. 2017. "Election 2016: Election Results." Townhall.com .

URL: https://townhall.com/election/2016/president/

Trump, Donald. 2020a. "Remarks by President Trump, Vice President Pence, and Members of the Coronavirus Task Force in Press Conference.".

URL: https://www.whitehouse.gov/briefings-statements/remarks-president-trump-vicepresident-pence-members-coronavirus-task-force-press-conference/

Trump, Donald J. 2020b. "Proclamation on Declaring a National Emergency Concerning the Novel Coronavirus Disease (COVID-19) Outbreak.". 
URL: https://www.whitehouse.gov/presidential-actions/proclamation-declaring-nationalemergency-concerning-novel-coronavirus-disease-covid-19-outbreak/

Zaller, John R. 1992. The nature and origins of mass opinion. Cambridge university press. 